\title{
Alginate encapsulation of Trichoderma harzianum against brown spot disease on rice (Oryzae sativa) in vivo assays
}

\author{
*Mohd Anuar, I.S., Ku Sulong, K.A., Abdul Ghani, H. and Wahab, M.Z. \\ Faculty Plantation and Agrotechnology, Universiti Teknologi MARA, 77300 Merlimau, Melaka, Malaysia
}

\author{
Article history: \\ Received: 22 July 2020 \\ Received in revised form: 4 \\ December 2020 \\ Accepted: 22 December 2020 \\ Available Online: 31 \\ December 2020
}

Keywords:

Trichoderma harzianum,

Brown spot,

Bipolaris oryzae

DOI:

https://doi.org/10.26656/fr.2017.4(S5).006

\begin{abstract}
Bipolaris oryzae causes brown spot disease which is one of the most devastating diseases in rice. Nowadays, biological methods are effective controls which need to be developed in order to use less chemical control. Therefore, the objectives of the present study were to characterize the $B$. oryzae as a biocontrol agent and to measure the performance of encapsulated T. harzianum in controlling brown spot disease. Bipolaris oryzae was characterized based on morphological characteristics and alginate encapsulation was produced from conidial suspension by adding sodium alginate and calcium chloride which results in small beads. Alginate formulation was applied to the rice seedling to find the result on this formulation. As a result, the application of encapsulation T. harzianum to control brown spot disease showed the inhibition of the disease. As a conclusion, this can be an alternative method to control brown spot disease which will render easier application to rice plantation in the future.
\end{abstract}

\section{Introduction}

Rice is cultivated at rained or irrigated lowland area which typically found on peninsular Malaysia (Rajamoorthy et al., 2015; Tiara et al., 2015). The production of rice in Malaysia is produced in small quantities and still lags compared to other countries in Asia (Tiara et al., 2015) who are depending the importation of rice from major suppliers such as Thailand, Vietnam and Pakistan due to its scarcity (Firdaus et al., 2012). In 2011, Food Agricultural Organization (FAO) stated that $0.4 \%$ out of $100 \%$ of the production of rice in Asia was produced in Malaysia, which only 2.7 million tonnes are from Peninsula, Sabah and Sarawak and it out of 656.4 million tonnes of rice in Asia produce. However, the production of rice become decrease due to the infection of the disease (Tiara et al., 2015).

Brown spot is a serious disease that attacks rice cultivation which is caused by Bipolaris oryzae. Besides Malaysia, brown spot disease was also reported in Japan, China, Burma, Sri Lanka, Bangladesh, Iran, Africa, Saudi Arabia, Russia, North America, Philippines, Australia and Thailand (Sunder, 2014). Brown spot disease has also reported causing enormous losses in grain yield up to $90 \%$ particularly (Ghose, 2000). This disease attacks several parts of a plant such as occurs on leaves, sheaths, panicle, glumes and grain. The symptoms of brown spot disease consist of brown, circular to oval spots that range in size from dark spots to oval spots up to one-half inch diameter. The colour of reddish-brown to brown is usually smaller than mature spots that have a grey centre with dark brown margins. These symptoms are seen on leaves in the growing stages until the maturity stage of rice (Kumari et al., 2015).

Nowadays, the world is more focused on alternative ways to control brown spot disease compared to using chemicals that are higher cost and possess more harmful effect. Biological control as alternatives has various benefits such as low cost, easy preparation and application, and is more environmental friendly (Khang et al., 2013). Trichoderma spp. was found to have potential as biocontrol agents including against brown spot disease. This Trichoderma antibiotics inhibit the growth of the pathogen in indirect ways (Kannangara et al., 2017). Moreover, the application of Trichoderma is proven to improve root, plant growth and also induces resistance in plants (Harman et al., 2004). Hence, by applying alginate formulation to replace chemical control in controlling the disease, this study aims to investigate biocontrol activities against $B$. oryzae using the encapsulation of Trichoderma isolates on rice. 


\section{Materials and methods}

\subsection{Isolation and identification of isolates}

Several infected disease symptoms on rice were randomly collected from Merlimau, Melaka. Bipolaris oryzae can be obtained from infected brown spot disease on rice using direct isolation and samples were cultured on Potato Dextrose Agar (PDA) for 7 days. T. harzianum were re-cultured from stock slants onto PDA medium. All these observations were recorded for identification purposes based on morphological characteristics according to Sivanesan (1987) and Ellies (1971). The isolate of $B$. oryzae was randomly selected and cultured on PDA medium at room temperature $27^{\circ} \mathrm{C}$ for 7 days. After that, the surface of $T$. harzianum was scraped to prepare the conidial suspensions and washing in sterile water. The fungal suspension was filtered and adjusted to $5 \times 10^{4}$ using a haemocytometer for conidial suspension. Then, pathogenicity test was carried out in the greenhouse to confirm the $B$. oryzae is the species that caused brown spot disease in rice.

\subsection{Preparation of alginate}

Trichoderma harzianum were grown onto PDA medium for 1 week at $28^{\circ} \mathrm{C}$. The agar surface submerged in sterile water was gently scraped with a cotton-tipped applicator for fungal suspension. To determine the number of viable conidia, dilutions of the spore suspensions were plated directly onto PDA medium. Conidial suspensions were used to prepare alginatecellulose or without cellulose pellets.

For the preparation of alginate encapsulation, $10 \mathrm{~g} / \mathrm{L}$ of sodium alginate was added to the fungal conidial suspension after adding the food base material $(10 \%$ cellulose) under sterile conditions. Next, to allow the homogenous dissolution of the polysaccharides the mixture was vigorously stirred. After that, the mixture was extruded through sterile plastic nozzles with a diameter of $1 \mathrm{~mm}$. An amount of $6 \mathrm{~g} / \mathrm{L} \mathrm{CaCl}_{2}$ solution where gelation of sodium alginate into a calcium alginate matrix was carried out. As a result, a small bead $(2 \mathrm{~mm}$, mean diameter) containing entrapped fungal conidia was obtained. Then, the beads were maintained in the $\mathrm{CaCl}_{2}$ solution at room temperature for 1 to $2 \mathrm{hrs}$. The $\mathrm{CaCl}_{2}$ solution was pumped out and the beads are washed twice with sterilized distilled water. The fresh beads were then used directly or kept at $4-5^{\circ} \mathrm{C}$ in sealed flasks for several days.

\subsection{Application of alginate}

The alginate formulation applied to the rice seedling was conducted by growing it at the nursery stage from the germinated seed. This method required the seedlings to grow up to 50 days. Next, three treatments were conducted using sterile distilled water and rice seedling as a control (Treatment 1), sterile distilled water, $B$. oryzae and rice seedling (Treatment 2) and alginate encapsulation, B. oryzae and rice seedling (Treatment 3 ). After 15 days of application, disease severity scale evaluation was used to confirm the effectiveness of alginate encapsulation based on IRRI (2015) as shown in Table 1.

Table 1. Disease severity scale for evaluation of brown spot of rice based on IRRI (2015)

\begin{tabular}{cc}
\hline Disease rating & Lesion size \\
\hline 0 & No disease or leaf and pots \\
1 & Small brown spot covering $<1 \%$ leaf area \\
3 & Brown sunken spots $1-10 \%$ leaf area \\
5 & Brown spots 11-25\% leaf area \\
7 & Circular brown sunken spots $25-50 \%$ leaf area \\
9 & Circular sunken spots 50-100\% leaf area \\
\hline
\end{tabular}

\section{Results and discussion}

\subsection{Morphological characterization}

$B$. oryzae was identified and verified through macroscopic and microscopic features based on a study by Ellies (1987) and Zibaee (2007). The present study found $B$. oryzae as the causal agent of brown spot disease displayed through dark greenish-grey colour on the colony for the upper and lower surface. Microscopically, the conidia shape was generally curved, light brown to golden brown, oval with brown pigmentations and had one to three septations which were similar to those described by several researchers (Ou, 1985; Saranraj et al., 2013) (Figure 1).

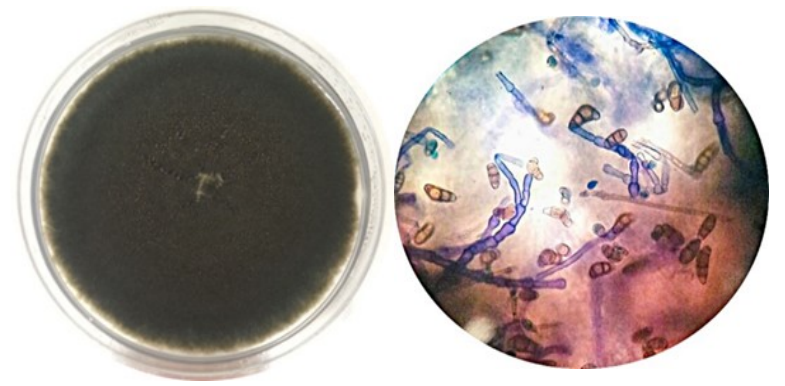

Figure 1. Colony colour and conidia of B. oryzae

\subsection{Pathogenicity test}

For pathogenicity tests, the disease severity starts to develop from day 3 until 7 with percentage disease severity of $15 \%$ to $83 \%$ with a score of 1 to 5 . As a result of pathogenicity tests, the isolates were confirmed as $B$. oryzae. Bipolaris oryzae is the most virulent species compared to other Bipolaris species (Saranraj et al., 2013).

Based on a study by Ou (1985), B. oryzae will infect parts of the rice plant including stubbles, straw and 
grains which act as the primary source of inoculum or primary infection. The subsequent lesion on leaves is mostly secondary infection initiated by air-borne spores produce from the primary infection. B. oryzae will penetrate the host through infection pegs which arise from appressoria. There is some protein contained in rice leaf such as aspartic acid, glutamic acid, alanine and methionine which will stimulate $B$. oryzae to colonize the leaf rice (Purkayastha and Mukhopadhyay, 1974).

\subsection{Effectiveness application of alginate encapsulation towards rice seedlings}

Trichoderma harzianum was encapsulated with alginate for further study on its effectiveness towards rice. Three treatments were conducted to observe the effectiveness of alginate encapsulation towards rice seedlings. Size of the lesion was observed each day until day 15 after inoculation of $B$. oryzae and the disease was evaluated based on severity according to IRRI (2015). The percentage of disease severity for Treatment 1 (control) is $0 \%$ which did not display any brown spot disease. The percentage disease severity for Treatment 2 (without alginate encapsulation) ranged from $59 \%$ to $70 \%$ with disease score 9 and the percentage disease severity for Treatment 3 (with alginate encapsulation) ranged from $21 \%$ to $25 \%$ with disease score 3 (Table 2).

Table 2. Development of B. oryzae from brown spot disease of rice without alginate encapsulation and with alginate encapsulation

\begin{tabular}{cccc}
\hline Method & Replication & Disease severity (\%) & Score \\
\hline & T1R1 & 66 & 9 \\
Without alginate & T1R2 & 60.8 & 9 \\
encapsulation & T1R3 & 59.6 & 9 \\
& T1R4 & 70 & 9 \\
& T1R5 & 70.55 & 9 \\
\hline \multirow{5}{*}{ With alginate } & T1R1 & 25.9 & 3 \\
encapsulation & T1R2 & 21.3 & 3 \\
& T1R3 & 22.75 & 3 \\
& T1R4 & 22.6 & 3 \\
& T1R5 & 23.9 & 3 \\
\hline
\end{tabular}

This is the first report on the formulation using alginate encapsulation of $T$. harzianum to control brown spot disease on rice in Malaysia. Based on Figure 2, clear differences of the severity of the disease between the application of alginate and without the application of alginate to control brown spot disease can be observed. The results on the effectiveness of $T$. harzianum as a biocontrol agent was proved by Gomathianagam et al. (2012), whereby $T$. harzianum and $T$. viride has potential to be a biocontrol agent against brown spot disease on rice. In addition to that, the Trichoderma species are known to have the ability to enhance plant resistance to disease, colonise plant roots, increase plant growth
(Harman et al., 2004), produce strong spores and survive in different environmental conditions. The Trichoderma species can compete with the pathogens with fastgrowing mycelium to prevent other pathogens from obtaining nutrient (Harman, 2000; Vinale et al., 2008).

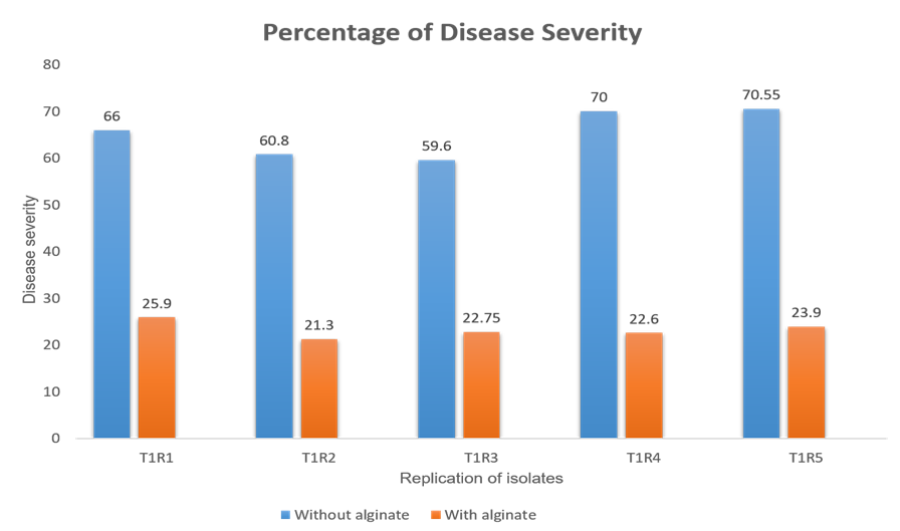

Figure 2. Percentage of Disease Severity

The application of $T$. harzianum as biological control can indirectly enhance the growth and development of rice. According to a study by Suparno (2016), the growth of rice can be observed by the increasing number of tiller and plant height. Besides that, using Trichoderma produces nutrients needed by plants to grow. According to Fravel (1988), the application of Trichoderma can increase the nitrogen content in the soil. Trichoderma also showed an increase in elongation of roots, leaves, wet and dry weight of plants (Gams and Bissett, 1998).

\section{Conclusion}

Based on our research findings it can be concluded that rice is an important cereal crop in Malaysia whereby demands are increasing day by day, followed by the increase in the human population. However, the production of rice decreases due to diseases such as the brown spot disease which is one of the most common and serious diseases in rice. Instead of applying chemical control, T. harzianum had been used as a biocontrol agent to monitor and prevent brown spot disease using alginate encapsulation. In the perspective of sustainable agriculture practices, using alginate encapsulation has been reported as effective is recognized as an environmentally friendly method.

\section{Conflict of interest}

The authors declare no conflict of interest.

\section{Acknowledgements}

The authors would like to acknowledge The Institute of Research Management and Innovation (IRMI) UiTM, Shah Alam, Selangor, Malaysia for the financial support 
of this research. This research is supported by IRMI, UiTM under the LESTARI Research Grant Scheme with project code: 600-IRMI/DANA 5/3/LESTARI (0071/2016).

\section{References}

Ellies, M.B. (1971). Dematiaceous Hyphomycetes. Surrey, UK: Kew, Commonwealth Mycological Institute.

Firdaus, R.B., Latiff, I.A. and Borkotoky, A.P. (2012). The impact of climate change towards Malaysian paddy farmers. Journal of Development and Agricultural Economics, 5(2), 57-66. https:// doi.org/10.5897/JDAE12.105

Gams, W. and Bissett, J. (1998). Morphology and identification of Trichoderma and Gliocladium. In Kubicek, C.P. and Harman, G.E. (Eds). Basic Biology, Taxonomy and Genetics, p. 3-34. Bristol, PA: Taylor and Francis.

Ghose, R.G. (2000). Rice in India. New Delhi: ICAR.

Gomathinayagam, S., Rekha, M., Sakthivel, M. and Jagessar, J.C. (2010). The biological control of paddy disease brown spot (Bipolaris oryzae) using Trichoderma viride in vitro condition. Journal of Biopesticides, 3, 93-95.

Harman, G.E. (2000). Myths and dogmas of biocontrol. Plant Disease, 84(4), 377-393. https:// doi.org/10.1094/PDIS.2000.84.4.377

Harman, G.E., Howell, C. R., Vitarbo, A., Chet, I. and Lorito, M. (2004). Trichoderma species opportunistic, avirulent plant symbionts. Nature Reviews Microbiology, 2, 43-56. https:// doi.org/10.1038/nrmicro797

IRRI. (2015). Standard evaluation system for rice. Los Banos, Manila, Philippines: IRRI.

Kannangara, S., Dharmathna, R.M. and Jayarathna, D.L. (2017). Isolation, Identification and Characterization of Trichoderma Species as a potential Biocontrol Agent against Ceratocystis paradoxa. The journal of Agriclutural Sciences, 11(3), 51-62. https:// doi.org/10.4038/jas.v12i1.8206

Khang, V.T., Anh, N.T., Tu, P.M. and Tham, N.T. (2013). Isolation and selection of Trichoderma spp. exhibiting high antifungal activities against major pathogens in Mekong Delta. Omonrice, 19, 159-171.

Kumari, S., Kumar, Atul. and Rani, Santwana. (2015). Morphological characterization of Bipolaris oryzae causing brown spot of paddy in Bihar, 1(5), 85-87.

Ou, S.H. (1985). Rice Diseases. 2nd ed. England: Commonwealth Mycological Institute.

Purkayastha, R.P. and Mukhopadhyay, R. (1979). Level of amino acids and post-infectional formation of antifungal substances in relation to susceptibility of rice plants against $P$. oryzae at different nitrogen supply. Journal of Plant Disease and Protection, 83 (4), 221-228.

Rajamoorthy, Y. and Munusamy, S. (2015). Rice industry in Malaysia: Challenges, Policies and Implications. Procedia Economics and Finance, 31, 861-867. https://doi.org/10.1016/S2212-5671(15) 01183-1

Saranraj, P., Sivasakthivelan, P. and S. Sivasakthi, S. (2013). Prevalence and production of plant growth promoting substance by Pseudomonas fluorescens isolated from paddy rhizosphere soil of Cuddalore district, Tamil Nadu, India. African Journal of Basic and Applied Sciences, 5(2), 95-101.

Sivanesan. (1987). Graminicolous species of Bipolaris, Curvularia, Drechslera, Exserohilum and their teleomorphs. Kew, UK: C.A.B. International Wallingford UK.

Sunder, S., Singh, R. and Agarwal, R. (2014). Brown Spot of Rice: An Overview. Indian Phytopath, 67(3), 201-215.

Suparno, Sukaso, Luchman, H. and Aidawati, N. (2016). Trichoderma spp. as agent of biological control in Local Rice disease in Tidal Swamp Lands in South Kalimantan, Indonesia. Journal of Agriculture and Veterinary Science, 9(1), 1-6.

Tiara, H., Murchie, E.H. and Warsi, A. (2015). Rice Production and Climate Change: A Case Study of Malaysian Rice. Tropical Agricultural Science, 38 (3), 321-328.

Vinale, F., Sivasithamparam, K., Ghisalberti, E., Marra, R., Woo, S. and Lorito, M. (2008). Trichodermaplant-pathogen interactions. Soil Biological Biochem, 40(1), 1-10. https://doi.org/10.1016/ j.soilbio.2007.07.002 